\title{
Proposta de melhoria do desempenho por meio da maturidade em gerenciamento de projetos
}

Helio Dragoni Jr${ }^{1}$

Alexandre Nabil Ghobril ${ }^{2}$

\begin{abstract}
Resumo
O principal objetivo deste trabalho é apresentar uma proposta para melhoria de desempenho no gerenciamento de projetos da empresa Engilab. Metodologicamente, o trabalho segue o protocolo de relato tecnológico, passando pelas etapas de análise, diagnóstico e proposta de solução. Após uma análise inicial de cenários e do desempenho dos projetos da empresa, foi aplicada uma pesquisa qualitativa para identificação de problemas na visão de gestores e executores dos projetos. Em seguida, analisou-se os principais modelos de avaliação de maturidade de projetos e a escolha do modelo MMGP (Modelo de Maturidade em Gestão de Projetos, criado por Darci Prado para avaliação do nível de maturidade em gestão de projetos). Após aplicação do questionário deste modelo, a empresa foi enquadrada no nível 3 de maturidade. A análise dos dados obtidos permitiu identificar pontos de melhoria e elaborar plano de ações que irá potencializar o aumento do nível de maturidade da empresa nos próximos dois anos.
\end{abstract}

Palavras-chave: Gerenciamento de projetos; Nível de maturidade em gerenciamento de projetos; Gestão de projetos; MMGP.

\begin{abstract}
The main objective of this article is to present a proposal for performance improvement in project management of Engilab. Methodologically, the work follows the protocol of technological reporting, passing through the stages of analysis, diagnosis and solution proposal. After an initial analysis of scenarios and the performance of the company's projects, a qualitative research was applied to identify problems in the view of managers and project executives. Next, we analyzed the main models of evaluation of maturity of projects and the selection of the MMGP tool (Maturity Model for Project Management, created by por Darci Prado for project management maturity assessment). After applying the MMGP questionnaire, the company was classified in level 3 of maturity. The analysis of
\end{abstract}

Mestre em Administração, Universidade Presbiteriana Mackenzie. São Paulo, SP - Brasil. junior.dragoni@gmail.com

Professor do Programa de Mestrado Profissional em Administração do Desenvolvimento de Negócios, Universidade Presbiteriana Mackenzie. São Paulo, SP - Brasil. ORCID: https://orcid.org/0000-0001-9866-0290. | alexandre.ghobril@mackenzie.br

Como citar:

Dragoni Jr, H., \& Ghobril, A. N. (2020). Proposta de melhoria do desempenho por meio da maturidade em gerenciamento de projetos. Revista Inovação, Projetos e Tecnologias, 8(1), 71-82.

https://doi.org/10.5585/iptec.v8i1.16039 
the data obtained allowed the identification of improvement points and the elaboration of an action plan that will increase the company's level of maturity in the next two years.

Keywords: Project management; Project management maturity level; Project management; MMGP.

\section{Introdução}

Um grande desafio da administração de projetos é atender às demandas cada vez mais exigentes do mercado quantos aos prazos, custos, escopo e qualidade. Nesse sentido, torna-se uma questão estratégica desenvolver o gerenciamento destes projetos de forma eficaz e eficiente para garantir seu sucesso.

Segundo Rabechini Jr. (2005), além das boas práticas de gerenciamento de projetos, o caminho a ser seguido para sua institucionalização apresenta grandes desafios pois, geralmente, afeta a cultura da empresa. Para que este caminho possa ser menos árduo, é aconselhável a adoção de um modelo de avaliação da maturidade em gestão de projetos, que permita um maior entendimento das forças e fraquezas da organização em gerir projetos, identificando o estágio de maturidade atual e abrindo caminhos que possibilitem o avanço da maturidade.

Nesse sentido, a partir de alguns sinais de insucesso no resultado dos projetos da empresa estudada, foi analisada a sua situação atual em gerenciamento destes projetos através do modelo de maturidade MMGP (Modelo de Maturidade em Gestão de Projetos), elaborado por Darci Prado, visando uma análise de seu nível de maturidade e seus pontos mais críticos, para a proposta de um plano de ação que contribua para o aumento do seu nível de maturidade, resultando na melhoria no desempenho de seus projetos e da performance da organização como um todo.

A Engilab (nome fictício) é uma multinacional americana criada na década de 1980, com o objetivo de projetar, fabricar e fornecer produtos e serviços para proteção, monitoramento, controle, automação, comunicação e medição de sistemas de energia elétrica em todo o mundo, atuando em inúmeros setores com soluções digitais e criativas, e com uma cultura de ganho de mercado pela inovação e excelência em seus produtos.

A subsidiária brasileira foi instalada no Brasil em 2000, com o objetivo de ganhar o mercado nacional e com perspectivas de crescimento a médio e longo prazo. Em seus primeiros anos, atuava unicamente com a venda de equipamentos importados, manufaturados na matriz americana, mas no início desta década iniciou as atividades de montagem de painéis elétricos e sistemas de energia que, em conjunto com os equipamentos produzidos e somados a serviços especializados de engenharia, fornecem soluções completas por meio de projetos customizados aos seus clientes. Estes por sua vez são, em sua maioria, empresas do setor de geração e distribuição de energia, além de grandes indústrias consumidoras de energia elétrica. Diante deste novo modelo de negócios, iniciou em 2012 a estruturação de sua equipe de projetos, que tem atuado no gerenciamento dos mesmos e no aprimoramento de seus processos.

Para os equipamentos eletrônicos avulsos, embora não seja líder de vendas, a empresa possui uma parcela do mercado formada por clientes fidelizados, devido à qualidade reconhecida de seus produtos e serviços e política de garantia aplicada. Mesmo com a forte concorrência com grandes empresas do mercado, é vista como pioneira em inovações e líder na qualidade dos produtos ofertados, permanecendo, por este motivo, relativamente estável e com margens controladas, visto que a principal variável relevante neste caso é a flutuação do dólar.

Já na área de projetos, que envolve a manufatura de painéis elétricos e serviços de engenharia, o cenário é adverso. Mesmo oferecendo ao mercado produtos de alta qualidade, devido ao valor dos insumos importados, dos serviços (por conta da mão-de-obra especializada) e, também, por conta do prazo de entrega (decorrente do tempo de fabricação e importação dos componentes), a empresa não 
tem alcançado resultados satisfatórios. Além disso, existe no mercado uma diversidade muito maior de concorrentes neste segmento e, por se tratar de projetos customizados, existem outras variáveis de desempenho que impactam no resultado.

Adicionalmente, o setor sofreu retração nos últimos anos em decorrência da crise econômica, evidenciada principalmente pela redução de investimentos no setor de energia, que gera impacto nos negócios da empresa. As principais vendas de painéis elétricos são geradas para empresas de geração, transmissão e distribuição de energia elétrica (GTD) e dependem principalmente de investimentos em modernização de subestações de energia elétrica, que não tem ocorrido nas dimensões esperadas, como pode ser observado nos dados da Tabela 1.

Tabela 1: Investimentos do Setor Elétrico em Ativos Fixos

\begin{tabular}{ccc}
\hline Ano & \% Faturamento & R\$ milhões \\
\hline 2011 & $3,20 \%$ & 4.380 \\
\hline 2012 & $2,60 \%$ & 3.732 \\
\hline 2013 & $2,70 \%$ & 4.168 \\
\hline 2014 & $2,50 \%$ & 3.831 \\
\hline 2015 & $2,30 \%$ & 3.236 \\
\hline 2016 & $1,80 \%$ & 2.381 \\
\hline 2017 & $1,80 \%$ & 2.508 \\
\hline
\end{tabular}

Fonte: ABINEE - Associação Brasileira da Ind. Elétrica e Eletrônica (2018)

A empresa possuía, até meados de 2016, uma estratégia agressiva de penetração no mercado brasileiro, mesmo que isso exigisse a realização de vendas com margens ínfimas ou até mesmo negativas. Neste contexto, ao mesmo tempo que suas vendas aumentavam, exigindo uma estrutura administrativa maior e consequente aumento de despesas, suas margens aplicadas caíam, ocasionando ao final, resultados insatisfatórios. Prova disso é a queda constante no resultado dos seus exercícios mais recentes, sobretudo em nos anos de 2016 e 2017 em que a empresa atingiu um prejuízo anual de 3,37 e 2,94 milhões de dólares, respectivamente.

Entre 2017 e 2018, a empresa passou por um processo de reestruturação com grandes mudanças em sua administração (alteração na alta administração e verticalização da estrutura hierárquica nas subsidiárias), que de um lado gerou uma maior autonomia e objetividade para a área na tomada de decisões e, de outro, passou a exigir um maior controle sobre os números e gerar maior responsabilidade sobre as decisões tomadas, impactando diretamente a área de gerenciamento de projetos, que possui interface com todos os demais departamentos.

Além disso, a companhia tem adotado novas estratégias, com redução das despesas e aplicação de novas e maiores margens, o que tem exigido maiores esforços na venda e no gerenciamento de projetos - onde há o maior impacto decorrente - sobretudo no atual cenário, onde temos uma economia crescente, mas ainda fraca. Neste sentido, é essencial tornar o processo de gerenciamento de projetos mais eficiente, em alinhamento com as diretrizes da empresa, tanto no sentido estratégico dos negócios, quanto no atendimento de sua visão, de ser uma empresa de excelência no setor.

O guia PMBOK (PMI, 2017) define um projeto como um esforço temporário empreendido para criar um produto, serviço ou resultado único e define o gerenciamento de projetos como sendo a aplicação de conhecimentos, habilidades, ferramentas e técnicas às atividades do projeto, a fim de cumprir os seus requisitos, ressaltando sua importância nas seguintes palavras: 
O gerenciamento de projetos permite que as organizações executem projetos de forma eficaz e eficiente. (...) Os projetos são uma maneira chave de criar valor e benefícios nas organizações. No ambiente de negócios atual, os líderes organizacionais precisam ser capazes de gerenciar orçamentos cada vez mais apertados, prazos mais curtos, recursos mais escassos e uma tecnologia que muda rapidamente. O ambiente de negócios é dinâmico, com um ritmo acelerado de mudança. Para se manterem competitivas na economia mundial, as empresas estão adotando o gerenciamento de projetos para entregar valor de negócio de forma consistente.

A empresa que busca a excelência nos resultados obtidos deve, portanto, aderir às boas práticas de gerenciamento de projetos, de modo a otimizar seus resultados continuamente e tornar o sucesso um resultado constante e estratégico. Conforme menciona Kerzner (2002), as organizações de reconhecida excelência na gestão de projetos criam um fluxo contínuo de projetos gerenciados com sucesso.

Com base em Rabechini Jr. (2005), pode-se afirmar que é a partir do gerenciamento de projetos que se pode atender ou superar as expectativas das partes interessadas (stakeholders), pois estas expectativas dependem do equilíbrio das exigências impostas pelo escopo, tempo, custo, qualidade, expectativas e necessidades das diferentes partes. Segundo Prado (2015), o mundo depende de projetos, pois quase um terço do PIB da economia mundial é gerado por meio de projetos.

Para realização deste trabalho, utilizou-se a pesquisa qualitativa com os gestores da empresa e o questionário do modelo MMGP, que possibilitou mensurar o atual nível de maturidade da organização no gerenciamento de projetos e indicar os principais pontos de melhoria para alavancagem deste nível. A seguir, será tratado em detalhes a metodologia utilizada, sua aplicação prática, a análise e discussão dos resultados, as conclusões e as referências bibliográfica utilizadas.

\section{Referencial teórico}

Diante do cenário atual, de retomada econômica, ainda com baixo nível de investimentos, alta concorrência e novas estratégias de negócios, é de vital importância que a empresa se mostre competitiva, sendo capaz de oferecer soluções que sejam financeira e cronologicamente viáveis, tanto aos clientes quanto à própria organização. Neste sentido, um importante fator para determinar o sucesso dos projetos é a forma com que a empresa gerencia estes projetos. Segundo Farias Filho e Almeida (2010), o Gerenciamento de Projetos está relacionado com a competência estratégica e pode melhorar significantemente a competitividade futura das organizações.

Kerzner (2012) pondera que quando as empresas desenvolvem sistemas e processos maduros, surgem dois benefícios: primeiro, o trabalho é executado com o mínimo de mudanças de escopo; segundo, os processos são definidos de maneira a causar o mínimo de problemas para o negócio principal da empresa.

Prado (2015) estabelece um projeto bem-sucedido como sendo aquele que atingiu a meta proposta. Isso geralmente significa que foi concluído e produziu os resultados e benefícios esperados, e os principais envolvidos ficaram plenamente satisfeitos. Espera-se que o projeto tenha sido encerrado dentro das exigências previstas para prazo, custo, escopo e qualidade.

Neste sentido, por meio de uma análise dos projetos da empresa no ano base 2017, considerouse que apenas $47 \%$ destes atingiram um nível considerado plenamente como nível de sucesso pela organização. 
De acordo com Zwikael e Globerson (2006) citado por Cardoso, Ziviani e Duarte (2017), algumas pesquisas confirmaram a existência de uma correlação positiva entre os benefícios oriundos de um maior desempenho, à medida que a organização atinge patamares de níveis mais elevados de maturidade.

Segundo Prado (2015), existe uma relação direta entre o nível de maturidade das empresas no gerenciamento de projetos e o sucesso obtido neste gerenciamento, conforme observa-se na Figura 1. Estes dados são baseados em pesquisas realizadas pelo autor, com base no modelo desenvolvido por ele (modelo MMGP) desde o ano de 2015 com empresas brasileiras de diversos segmentos e estão disponíveis no site da pesquisa, chamada de Maturity Research.

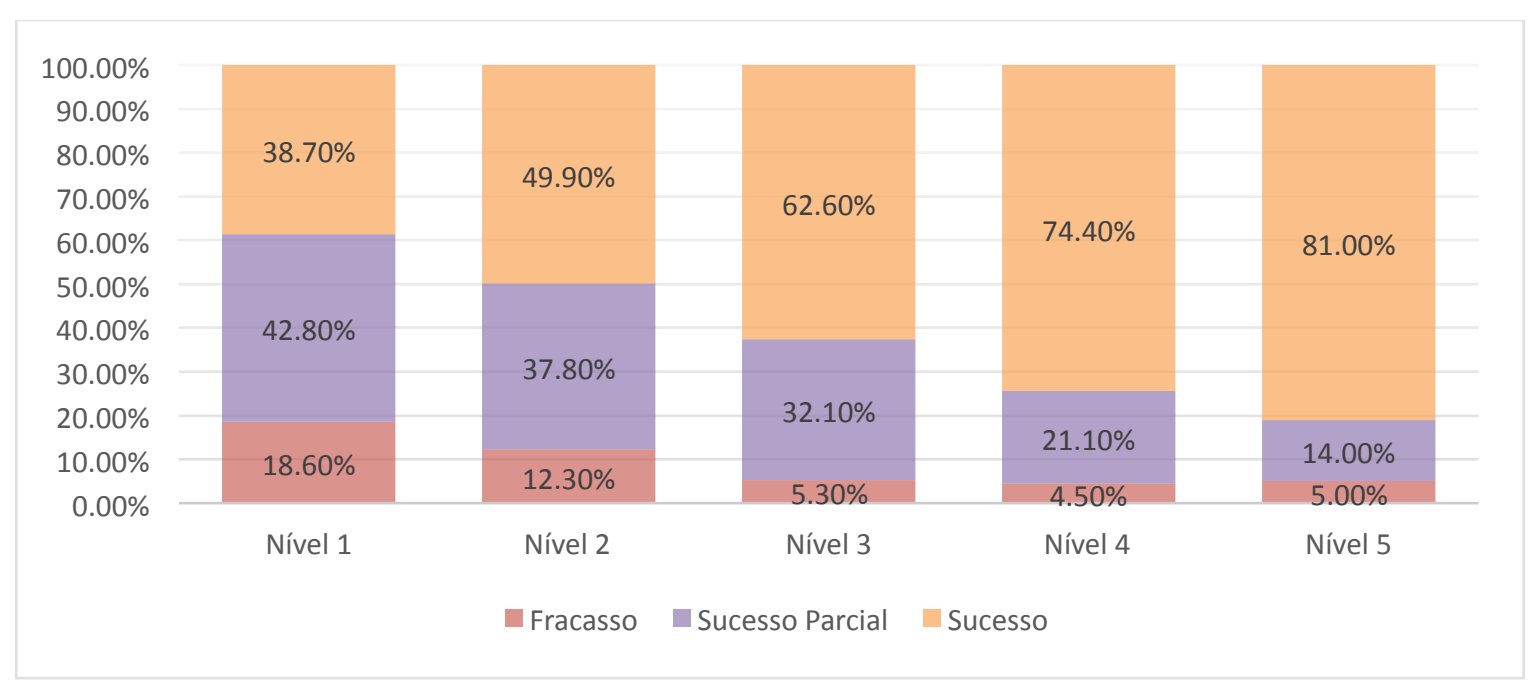

Figura 1 - Relação Sucesso x Nível de maturidade

Fonte: Prado (2015).

Assim, considera-se que o problema a ser trabalhado consiste, sumariamente, no fato de que a empresa não possui o nível de maturidade necessário no gerenciamento de seus projetos. Rabechini Jr. e Pessôa (2015) ponderam que investir na adoção de maturidade em gerenciamento de projetos é uma questão estratégica, nas diversas lideranças empresariais. Isto pode ser percebido pelo crescimento de interessados em entender e se profissionalizar em gerenciamento de projetos. Complementando, Prado (2015) considera que um maior amadurecimento no gerenciamento de projetos propicia menores prazos, maior aderência aos custos previstos e entrega de resultados (ou outcomes) conforme esperado.

A maturidade em gerenciamento de projetos pode ser definida como a concepção de sistemas e processos que compõe o desenvolvimento de um projeto, sendo estes por sua natureza repetitivos e que, portanto, garantem uma alta probabilidade de que cada um deles seja um sucesso. É composta por um conjunto de ferramentas que têm por objetivo auxiliar as empresas a alcançar a maturidade no gerenciamento de seus projetos, como por exemplo, por meio da identificação das melhores práticas, realizadas por empresas líderes de mercado (Kezner, 2002).

O objetivo deste trabalho é, portanto, potencializar o aumento do nível de maturidade no gerenciamento de projetos da empresa e, desta forma, melhorar o resultado de seus projetos, identificando pontos críticos e propondo um plano de ação para o aprimoramento destes pontos e do seu processo como um todo. 


\section{Metodologia}

De acordo com Marcondes, Miguel, Franklin e Perez (2017), a pesquisa aplicada parte de questões concretas para obter informações visando a decisões de negócios, a problemas e a oportunidades e para tornar claros os aspectos que favorecem ou ameaçam os negócios da empresa. Neste sentido, primeiramente foi realizada uma análise da situação dos projetos da empresa, tendo como base o ano de 2017, por meio do relatório anual final da empresa, de 31 de dezembro de 2017. Por meio de uma análise dos projetos da empresa no período mencionado, notou-se que dentre 136 projetos, 81 tiveram variações de margem de lucro superiores à $5 \%$ (o limite de $5 \%$ seria o aceitável pela organização), sendo 43 deles com variação negativa (isto é, perda de margem). Destes projetos, mais de 50\% tiveram estouro de prazo (não há número exato, pois não há registro claro que evidencie se as reprogramações são por solicitação do cliente ou decorrentes de atraso) ou de escopo (considerando-se utilização de mais horas de trabalho que o previsto) durante sua execução, gerando não apenas a perda de produtividade e aumentos de custos mas, em alguns casos, insatisfação por parte dos clientes impactados.

Em seguida, foi preparado um roteiro de perguntas e aplicada uma pesquisa qualitativa estruturada a alguns gestores envolvidos diretamente com o gerenciamento de projetos, com foco na identificação de problemas existentes no atual processo de gerenciamento. Na sequência, após a análise e síntese destas entrevistas, foram levantadas algumas hipóteses relacionadas ao desempenho obtido e esperado pela organização.

Segundo Almeida, Francesconi e Fernandes (2018), as pesquisas qualitativas, na maioria das vezes, têm caráter exploratório: estimulam os entrevistados a pensar e falar livremente sobre algum tema, objeto ou conceito. Elas fazer surgir aspectos subjetivos, motivações implícitas, ou mesmo não conscientes de forma espontânea.

Neste caso, foram realizadas três entrevistas semi-estruturadas, com três envolvidos diretamente com o gerenciamento de projetos, sendo um administrador de projetos sênior, responsável por projetos de grande porte e estratégicos, o coordenador de projetos, responsável pela equipe de gerenciamento de projetos e o vice-presidente de engenharia e serviços, que é responsável, entre outras atribuições, pela área de projetos a nível mundial.

Por meio da análise das respostas, nota-se que a empresa ainda não possui um gerenciamento eficiente, evidenciado por: carência de planejamento de recursos, ou impossibilidade de planejamento decorrente do volume de recursos disponíveis; divergência entre o que é planejado e o que é realizado, em relação à programação de atividades; necessidade de informações em tempo real para apoio à tomada de decisão, acompanhamento e operacionalização de custos, que suportem o gerenciamento dos projetos, juntamente com KPIs (Key Performance Indicators) adequados; pouca clareza da equipe com relação às responsabilidades e obrigações para com as atividades e projetos; ausência de alinhamento claro entre os envolvidos no processo com relação ao papel e importância do gerenciamento de projetos.

Além disso, a discrepância das respostas sobre "a relevância das dificuldades e deficiências existentes para o alcance dos objetivos dos negócios" em cada cargo entrevistado - e, consequentemente, em cada nível hierárquico - mostra também um certo distanciamento da compreensão da importância do gerenciamento de projetos em cargos hierarquicamente superiores.

Assim, obtém-se como principal hipótese que o desenvolvimento do gerenciamento de projetos não tem evoluído na proporção da necessidade da empresa e nem na direção do seu desenvolvimento estratégico, incorrendo necessidade de nivelamento das bases deste gerenciamento (informatização, metodologia estratégia, competências humanas e de gestão).

Ao longo da análise, pode-se observar que existem fatores diversos que contribuem para o não 
sucesso dos projetos existentes na empresa, incluindo fatores humanos (desenvolvimento, estímulo, envolvimento, etc.), tecnológicos (ausência de ferramentas e indicadores apropriados), processuais (processos com pontos visíveis de melhoria), dentre outros.

Diante de um cenário composto por vários problemas menores, que compõe uma situaçãoproblema maior, optou-se pelo uso de um modelo de diagnóstico do nível de maturidade da empresa no gerenciamento de projetos.

Segundo Prado (2015), um modelo de maturidade é um mecanismo capaz de quantificar numericamente a capacidade de uma organização de gerenciar projetos com sucesso, além de esperar-se que seja capaz de auxiliar no estabelecimento de um plano de crescimento para a maturidade da organização. Cardoso et al. (2017) ressaltam que é de grande importância que as organizações tenham o conhecimento do estágio atual de maturidade no gerenciamento de seus projetos e o seu posicionamento perante os concorrentes do mercado.

Investir na adoção de maturidade em gerenciamento de projetos está sendo uma preocupação estratégica, nas diversas lideranças empresariais (Rabechini Jr, 2015).

Os modelos de maturidade podem, segundo Cardoso et al. (2017), ser utilizados para a equiparação do nível de maturidade pelo fato de serem ferramentas que expressem quantitativamente o grau de maturidade em estágios pré-definidos.

Nesse sentido, foram avaliados três dos principais modelos de diagnóstico de maturidade: o OPM3 (Organizational Project Management Maturity Model), o PMMM (Project Management Maturity Model) e o MMGP (Modelo de Maturidade em Gerenciamento de Projetos).

O primeiro deles, o OPM3 (Organizational Project Management Maturity Model) foi desenvolvido pelo PMI e tem como foco o diagnóstico do nível de maturidade por meio de uma lista de itens para avaliação do estágio de competência das organizações e apresentando passos para se chegar a um novo estágio, dentro de uma divisão de quatro níveis e contemplando três dimensões: conhecimento, avaliação e melhoria.

O segundo modelo, o PMMM (Project Management Maturity Model), foi desenvolvido pela PM Solutions e tenta posicionar a organização dentro de uma escala de um a cinco, conforme sua maturidade e dentro de dimensões como: projetos estratégicos, expectativas de clientes, competitividade, entendimento executivo, desenvolvimento de novos produtos e eficiência/eficácia.

Já o terceiro modelo, o MMGP, desenvolvido pelo Consultor Darci Prado da Falconi Consultores de Resultado, também posiciona a organização dentro de uma escala de 5 níveis, contemplando as dimensões de: competência em gerenciamento de projetos, competência comportamental, competência técnica e contextual, alinhamento estratégico, metodologia, informatização e estrutura organizacional.

De acordo com Morais, Souza e Canholi Junior (2012), o modelo MMGP tem tido considerável aceitação no Brasil, como meio das organizações avaliarem sua maturidade, compararem com outras do mesmo segmento e para estabelecerem planos de crescimento. Adicionalmente, conforme menciona Silva (2011), este modelo mostra-se como o mais adequado considerando-se, principalmente, os quesitos aplicabilidade e benchmarking com outras indústrias e dimensões abordadas.

Desta forma, o modelo escolhido foi o MMGP, que se assemelha aos demais em alguns critérios, contudo sua principal diferença está nas suas variáveis de análise, que conseguem determinar o nível de maturidade em cada uma delas ao longo de cada nível do modelo, e assim, possibilitar ações mais específicas conforme necessidade. Além disso, trata-se de um modelo brasileiro, que vem sendo aprimorado desde sua primeira versão em 2002, tornando-se mais robusto e focado nas empresas brasileiras. Entende-se também que, por ser um modelo mais sintético (40 
questões) e ao mesmo tempo robusto (além do questionário há um rigoroso processo de diagnóstico da situação atual), poderá trazer resultados mais rápidos e simplificados, além de fornecer ferramentas para o estabelecimento de um plano estruturado de crescimento.

A análise da atual situação da empresa com relação ao gerenciamento de projetos foi realizada por meio do MMGP- Modelo de Maturidade em Gerenciamento de Projetos. As premissas utilizadas na sua adoção foram: ser compacto (possui para sua aplicação um questionário de 40 questões); ser simples de usar; ser confiável; fornecer resultados coerentes (robusto); possuir universalidade (poder ser utilizado por diferentes categorias de projetos); ser capaz de medir aspectos que estão realmente ligados ao sucesso no gerenciamento de projetos; e poder ser utilizado no estabelecimento de um plano de crescimento (Prado, 2015).

O modelo MMGP é composto sete dimensões, cada uma delas avaliada em cinco níveis, onde a organização pode ser enquadrada de acordo com seu nível de maturidade. As sete dimensões se relacionam com os cinco níveis, conforme mostrado na Tabela 2.

\begin{tabular}{c|c|c|c|c|c|c|c}
\hline \multirow{2}{*}{ NíVEL } & \multicolumn{7}{|c|}{ DIMENSÕES DA MATURIDADE } \\
\cline { 2 - 8 } & $\begin{array}{c}\text { COMPETÊNCIA } \\
\text { EM GP }\end{array}$ & $\begin{array}{c}\text { COMPETÊNCIA } \\
\text { TÉCNICA E } \\
\text { CONTEXTUAL }\end{array}$ & $\begin{array}{c}\text { COMPETÊNCIA } \\
\text { COMPORTAMENTAL }\end{array}$ & METODOLOGIA & INFORMATIZAÇÃo & $\begin{array}{c}\text { ESTRUTURA } \\
\text { ORGANIZACIONAL }\end{array}$ & $\begin{array}{c}\text { ALINHAMENTO } \\
\text { ESTRATÉGICO }\end{array}$ \\
\hline $\mathbf{5}$ & Otimizada & Otimizada & Madura & Otimizada & Otimizada & Otimizada & Otimizada \\
\hline $\mathbf{4}$ & Muito avançada & Forte avanço & Forte avanço & $\begin{array}{c}\text { Aperfeiçoada, } \\
\text { estabilizada e } \\
\text { em uso }\end{array}$ & $\begin{array}{c}\text { Aperfeiçoada, } \\
\text { estabilizada e em } \\
\text { uso }\end{array}$ & $\begin{array}{c}\text { Aperfeiçoada, } \\
\text { estabilizada e } \\
\text { em uso }\end{array}$ & Alinhado \\
\hline $\mathbf{3}$ & $\begin{array}{c}\text { Sigificativo } \\
\text { avanço }\end{array}$ & Algum avanço & Mais avanço & $\begin{array}{c}\text { Padronizada e } \\
\text { em uso }\end{array}$ & $\begin{array}{c}\text { Padronizada e em } \\
\text { uso }\end{array}$ & $\begin{array}{c}\text { Padronizada e } \\
\text { em uso }\end{array}$ & $\begin{array}{c}\text { Significativo } \\
\text { avanço }\end{array}$ \\
\hline $\mathbf{2}$ & Básica & Básica & Algum avanço & $\begin{array}{c}\text { Fala-se sobre o } \\
\text { assunto }\end{array}$ & $\begin{array}{c}\text { Software para } \\
\text { tempo }\end{array}$ & $\begin{array}{c}\text { Nomeia-se um } \\
\text { responsável }\end{array}$ & Desalinhamento \\
\hline $\mathbf{1}$ & Não há & Básica & Boa vontade & Não há & Dispersa & Não há & Desalinhamento \\
\hline
\end{tabular}

Tabela 2: Características das dimensões da maturidade conforme níveis do modelo MMGP Fonte: Prado (2015)

\section{$4 \quad$ Análise e discussão dos resultados}

O questionário do modelo MMGP, composto por 40 perguntas, foi aplicado a nove profissionais da Engilab (que são envolvidos diretamente com o processo de gerenciamento de projetos: três administradores de projetos, coordenador de projetos, coordenador de engenharia, gerente de produção, coordenador de suprimentos, gerente de qualidade e engenheiro auditor interno da qualidade).

A análise das dimensões e dos níveis do modelo MMPG possibilita duas visões: em qual ponto a organização se encontra no que diz respeito à sua maturidade (Nível de Maturidade) e de quais as dimensões (ou características) mais maduras e mais deficitárias dentro deste cenário (Dimensões da Maturidade).

Desta forma, como a pontuação final obtida foi de 199,5, a avaliação do Nível de Maturidade, seguindo o modelo de Prado (2015), é calculada da seguinte forma:

$\underline{\text { Soma da pontuação total obtida nos quatro blocos }(199,5)+100}$

100

O resultado obtido classifica a Engilab no nível de maturidade 3. Este índice mostra que a 
empresa está entre o nível de maturidade 2 (conhecido) e 3 (padronizado).

Já na visão de aderência às Dimensões da Maturidade, foi elaborado o Gráfico Radar de indicadores (figura 2) para uma melhor visualização, O modelo, que Mosley e Mayer (1999) denominam como "Gráfico da Teia de Aranha" (Spider Web Chart), oferece em clareza e utilidade, pois propicia facilidade para comparação de desempenho numa análise multidimensional.

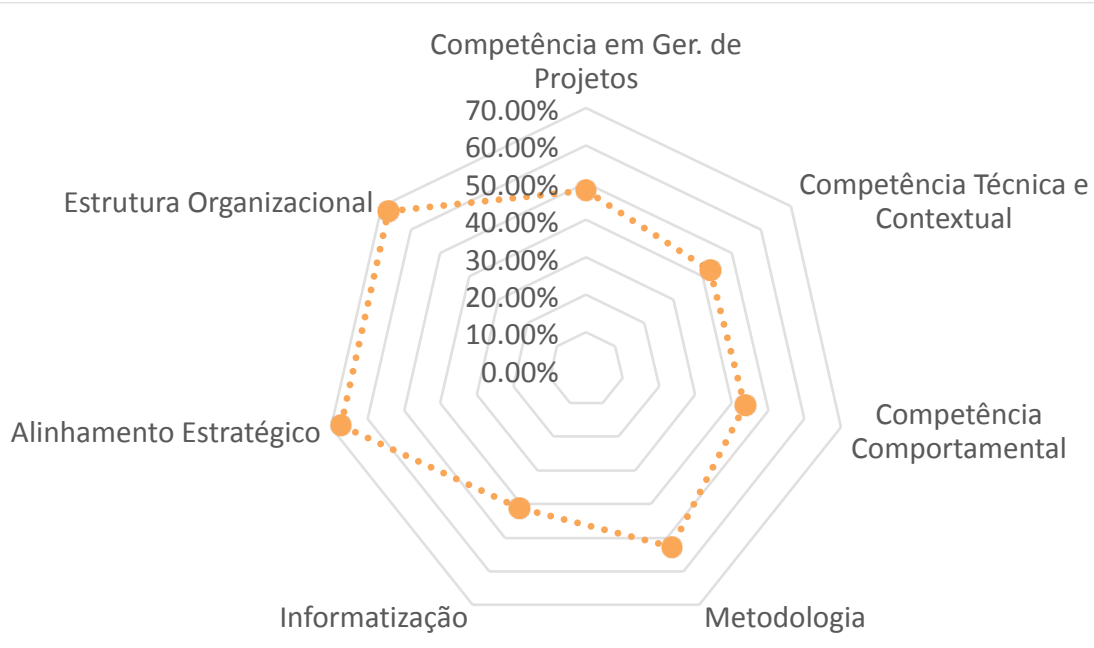

Figura 2 - Visualização gráfica da aderência da Engilab às dimensões da maturidade

Fonte: Elaborado pelos autores.

O modelo MMGP, por meio de uma pesquisa aplicada anualmente pelo seu criador Darci Prado e sua equipe, possibilita a realização de uma comparação do resultado da avaliação da maturidade com a realidade do cenário brasileiro. Prado (2015) menciona que a experiência com a pesquisa de maturidade desde 2005 possibilitou afirmar com muita convicção que, para organizações pressionadas pelo mercado, é muito pertinente a escolha do valor 4,0 como benchmarking (comparação dos resultados) para a maturidade, sendo que, para valores acima dessa maturidade, o nível de sucesso está acima de $80 \%$. A visualização gráfica desta comparação, pode ser observada na Figura 3.

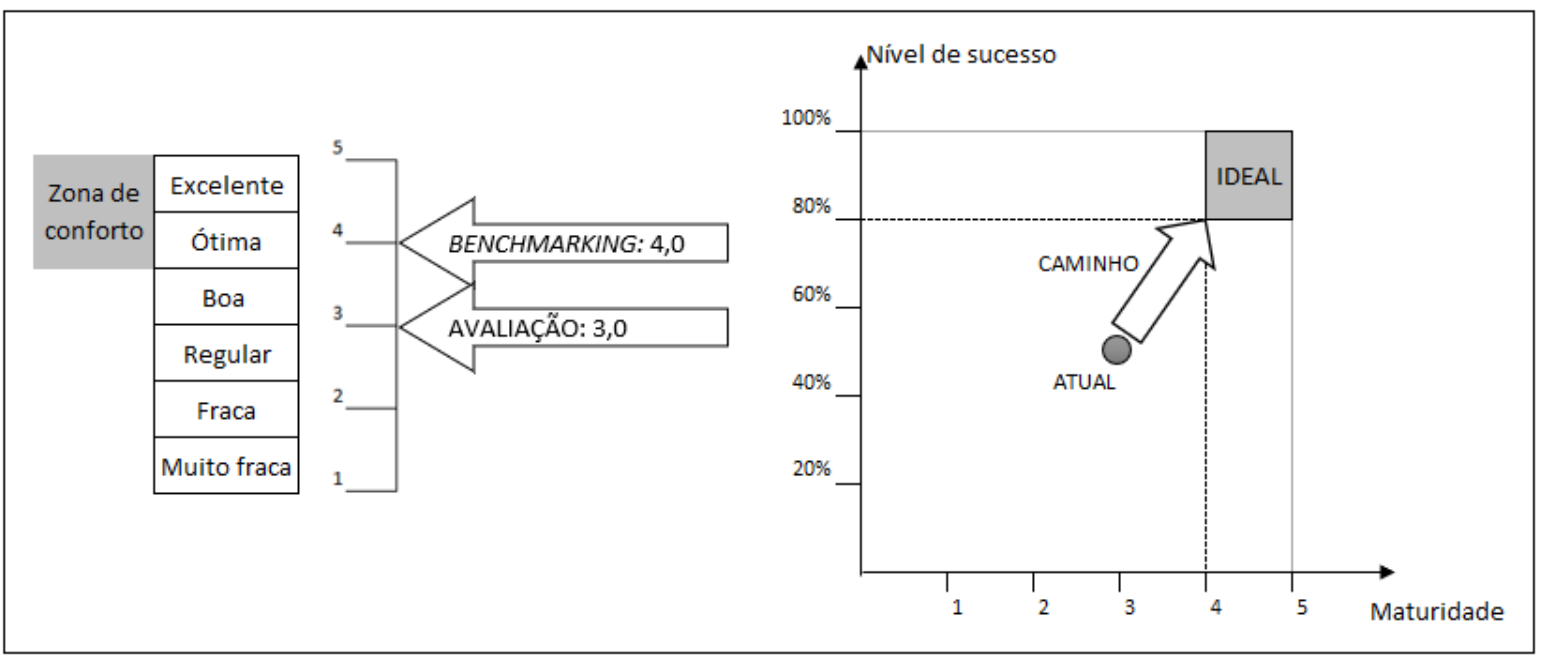

Figura 3 - Comparação dos resultados (benchmarking)

Fonte: Elaborado pelos autores com base em Prado (2015). 
Prado (2015) pondera a importância da elaboração de um plano de crescimento, visto que melhorar o nível de maturidade pode ser um desafio muito complexo, principalmente em casos em que o trabalho dos projetos do setor envolva uma estrutura matricial, ou seja, envolva diversos outros setores da organização com os quais interage - que é o caso da organização em questão.

Foi exposto ao gestor responsável pelo acompanhamento a situação atual da empresa quanto ao seu nível atual de maturidade (3) e acordado o estabelecimento de ações para o atingimento do nível de maturidade 4 (gerenciado). Foi estabelecido um plano de ações para o aumento do nível de maturidade através da análise dos processos existentes e das competências avaliadas na pesquisa aplicada, dos pontos fracos e suas causas e da viabilidade das ações propostas, criando-se um cronograma físico e financeiro apresentados à empresa.

Com base na proposta de Prado (2015), foi analisado em conjunto com o gestor responsável, o resultado de cada uma das 40 questões, considerando-se qual a nota obtida e estabelecendo-se uma nota desejada para obtenção após o final da implementação das ações. Para cada uma as questões, foi analisada a causa principal ou os pontos fracos que podem estar causando a deficiência e definida contramedida que será utilizada como base para elaboração do plano de ações.

Ao final, espera-se obter um aumento total de 98,4 pontos em relação ao resultado atual, que resultará em um novo valor de maturidade de 3,98, elevando o nível atual de maturidade em 1 ponto, conforme meta definida.

Segundo Marcondes et al. (2017), como toda melhoria implica mudanças, o plano de ações é necessário para dar disciplina e racionalidade ao processo, tendo em vista que este está sempre sujeito a fatores imponderáveis e restritivos, especialmente os de natureza político cultural do ambiente, comuns em mudanças organizacionais.

Ainda com base em Marcondes et al. (2017), para cada ação proposta, é essencial que se avalie os riscos existentes, a fim de garantir a eficácia dos resultados esperados. Desta forma, foi também elaborado juntamente com o gestor responsável o mapa de riscos para cada uma das ações elencadas. As ações foram dispostas dentro de um horizonte de execução de 24 meses, considerando períodos de planejamento, implementação, acompanhamento e ajuste.

Adicionalmente, considerando-se que as dimensões da maturidade com os resultados mais baixos na avaliação foram: informatização, competências em gerenciamento de projetos, competência técnica e contextual e competência comportamental, foi recomendado ao gestor responsável que, em quaisquer outras ações de melhoria da organização que possam ser definidas, estas quatro dimensões sejam priorizadas.

Espera-se, desta forma, que as ações propostas possibilitem, complementarmente, o desenvolvimento de habilidades e capacidades dos profissionais e da própria organização.

\section{Conclusão}

No presente estudo, buscou-se mensurar o nível de maturidade da empresa estudada de forma a possibilitar a posterior alavancagem desta maturidade pela definição de ações de melhoria. Baseouse, para isso, no método de relato tecnológico de Marcondes et al. (2017) para solução de problemas e aproveitamento de oportunidades, com as etapas de análise do contexto e realidade investigada, entendimento do problema, diagnóstico e proposta de solução.

$\mathrm{Na}$ etapa de entendimento do problema, foram identificadas as preocupações dos gestores, sua visão sobre as ineficiências da organização no tocante ao gerenciamento de projetos, o alinhamento do projeto com a estratégia organizacional, dada a relevância que a eficácia e a eficiência dos projetos têm sobre o resultado e sustentabilidade do negócio. 
Na etapa do diagnóstico do grau de maturidade atual da empresa na gestão de projetos, foi definida a metodologia e aplicado o questionário a um grupo de nove profissionais envolvidos diretamente com o processo de gerenciamento de projetos na Engilab. Os dados foram tabulados e permitiram análises, seja em termos de nível de maturidade, seja em termos de competências existentes e prementes de melhoria na organização, possibilitando a definição do nível atual de maturidade, de metas para aumento deste nível, e ações diretas para seu atingimento.

A cada etapa os resultados foram discutidos com os gestores, que participaram e apoiaram todo o andamento deste trabalho e, ao final, foi-lhes entregue um relatório gerencial que serviu de apoio à tomada de decisão e ao planejamento da organização.

O plano de ação elaborado será uma importante ferramenta para obtenção de melhorias e geração de valor, além de um importante diferencial estratégico para a organização. O sucesso parcial de sua carteira de projetos era visto como uma realidade difícil de ser modificada, como algo inerente ao negócio. Contudo, com a aplicação de um modelo estruturado, espera-se potencializar a melhoria no desempenho da organização, resultando em um maior nível de sucesso no gerenciamento de seus projetos, que é o objetivo principal deste trabalho.

Ressalte-se a importância acadêmica e prática dessa pesquisa. Do ponto de vista acadêmico, a análise das ferramentas e da adequabilidade destas aos objetivos da organização pode servir de referência para replicabilidade do estudo em outras empresas. Do ponto de vista prático, o relato tecnológico, que parte da análise de contexto, na validação interna do projeto, no diagnóstico e chega na proposta de solução, mostra como uma organização que opera com projetos complexos pode planejar e executar um plano de ações que resultem em maior controle dos processos, minimização de riscos, melhor monitoramento da lucratividade e criação de valor para seus clientes.

\section{Referências}

ABINEE. (2018). Desempenho Setorial. Recuperado em 10 de setembro de 2018 de: http://www.abinee.org.br/abinee /decon/decon15.htm

Almeida, M. I. R., Francesconi, M., \& Fernandes, P. P. (2018). Manual para desenvolvimento de pesquisa profissional. São Paulo. Editora Atlas.

Cardoso, D. R., Ziviani, F., \& Duarte, L. O. B. (2017). Gerenciamento de Projetos: Uma Análise da Maturidade do Setor de Mineração, Revista de Gestão e Projetos, 8(1), 01-15.

Farias Filho, J. R., \& Almeida, N. de O. (2010). Definindo o Sucesso em Projetos, Revista Gestão e Projetos, $1(2), 68-85$.

Kerzner, H. (2002). Gestão de Projetos: as melhores práticas. Porto Alegre. Editora Bookman.

Marcondes, R. C.; Miguel, L. A. P., Franklin, M. A., \& Perez, G. (2017). Metodologia para elaboração de trabalhos práticos e aplicados: Recuperado de http://up.mackenzie.br/stricto-sensu/administracao-dodesenvolvi-mento-de-negocios-profissional/

Morais, N. M., Souza, A. K. M., \& Canholi Junior, C. (2012). O caminho para a maturidade em gerenciamento de projetos: o caso da Companhia de Água e Esgoto do Ceará. SEGeT - Simpósio de Excelência em Gestão e Tecnologia Resende, RS. Recuperado em 20 de novembro de 2018 de: https://www.aedb.br/seget/arquivos/artigos12/35316346.pdf.

Mosley, H., \& Mayer, A. (1999). Benchmarking National Labour Market Performance: a Radar Chart Approach. Berlin, Wissenschaftszentrum Berlin für Sozialforschung. Discussion Paper March 1999 ISSN Nr. 1011-9523.

Prado, D. (2015). Maturidade em Gerenciamenteo do Projetos. 3 ed. Nova Lima. Falconi Editora. 
Project Management Institute - PMI. (2017). Um guia do conhecimento em gerenciamento de projetos (Guia PMBOK). Newtown Square. Project Management Institute.

Rabechini Jr., R. (2005). Competências e Maturidade em Gestão de Projetos. São Paulo. Editora Annablume.

Rabechini Jr., R. \& Pessôa, M. S. de P. (2015). Um modelo estruturado de competências e maturidade em gerenciamento de projetos, Revista Produção, 15(1), 34-43.

Silva, R. R. (2011). Análise comparativa de modelos de maturidade em gerenciamento de projetos: uma contribuição ao estudo da maturidade organizacional em setores de engenharia. Dissertação de Mestrado. Universidade Federal do Rio Grande do Norte, Natal, RN, Brasil. Recuperado em 20 de novembro de 2018 de: https://repositorio.ufrn.br/jspui/handle/123456789/15022. 